\title{
Personality profiling may help select better cleaner fish for sea-lice control in salmon farming
}

\author{
Benjamin Alexander Whittaker ${ }^{1}$, Sofia Consuegra, Carlos Garcia de Leaniz \\ Department of Biosciences, Centre for Sustainable Aquatic Research, Swansea University, Swansea, United Kingdom
}

\section{A R T I C L E I N F O}

\section{Keywords:}

Cleaner fish

Activity

Neophobia

Sociality

Aggression

Repeatability

\begin{abstract}
A B S T R A C T
Lumpfish (Cyclopterus lumpus) are increasingly being used as cleaner fish to control parasitic sea-lice in salmon farming, but cleaning rates are very variable and not all individuals eat sea-lice, which increases the risk of emaciation and has ethical and practical implications. Selecting good cleaners is a priority to make the industry more sustainable, but there is little information on what behaviours make cleaner fish effective under a commercial setting. We examined variation in lumpfish personalities according to the five-factor personality model that takes into account differences in activity, anxiety (shelter use, thigmotaxis), aggression, sociality, and boldness (neophobia). We then quantified how variation in lumpfish personalities influenced interactions with naïve Atlantic salmon (Salmo salar), without the confounding effects of variation in sea-lice loads. Variation in activity, sociality, aggression and neophobia, but not in anxiety, was repeatable. Neophilic, non-aggressive lumpfish spent more time inspecting salmon than neophobic and aggressive individuals, but salmon fled in the presence of the most active and social individuals, suggesting there may be an optimal cleaner fish personality amenable to artificial selection. The personality screening protocols developed in this study could inform a more efficient use of cleaner fish in salmon farming and reduce the number of individuals required to control sea-lice.
\end{abstract}

\section{Introduction}

Various species of wrasse (family Labridae) and lumpfish (Cyclopterus lumpus) are increasingly being used as facultative cleaner fish to remove parasitic sea-lice from farmed salmon (Powell et al., 2018b; Treasurer, 2018a, 2018b). Using facultative cleaner fish for pest control offers many advantages over chemical methods (Powell et al., 2018b), but relies on cleaner fish engaging in parasite removal (delousing) under a commercial setting. However, in the wild lumpfish do not generally feed on sea-lice, or act as cleaner fish (Davenport, 1985; Powell et al., 2018a), which poses a challenge for optimizing their use in salmon farming. Lumpfish are opportunistic generalist feeders and some may graze on sea-lice in salmon cages, especially when alternate food sources are limited (Imsland et al., 2015a, 2016a). Typically only 13-38\% of lumpfish consume sea-lice in salmon cages (Eliasen et al., 2018; Imsland et al., 2015a, 2014, 2016b), the majority feed on salmon pellets or graze on plankton (Johannesen et al., 2018), particularly during the summer (Eliasen et al., 2018). This has attracted criticism from regulatory agencies and animal welfare organisations, who point out that many cleaner fish die of malnutrition and suffer from low welfare because they are being used for a task they do not naturally do (European Union Reference Laboratory for Fish Diseases, 2016; Stranden, 2020). A call has been made for the use of cleaner fish to stop until their welfare can be guaranteed and the sources of mortality are addressed (Compassion in World Farming, 2018; OneKind, 2018). There is, therefore, a need to select individuals that readily engage in cleaning behaviour and consume sea-lice, as this would increase delousing rates with fewer cleaner fish, improve welfare, and reduce the risk of emaciation (Gutierrez Rabadan et al., 2021).

Lumpfish can be effective cleaners (Imsland et al., 2014, 2018) and reduce sea-lice loads on salmon clients by as much as $93 \%$ under the right conditions (Imsland et al., 2016b), but seemingly this is because certain individuals do most of the cleaning. Individual variation in cleaning behaviour is common among facultative cleaner fish, and some individuals may attend clients and engage in cleaning, while others ignore them (Morado et al., 2019). Understanding such variation is important because cleaning behaviour appears to be inherited (Imsland et al., 2016b), and the ability to screen individuals with a predisposition

\footnotetext{
* Corresponding author.

E-mail address: c.garciadeleaniz@swansea.ac.uk (C. Garcia de Leaniz).

1 Present address: University of Guelph, Department of Integrative Biology, Canada.
} 
for cleaning may facilitate a selective breeding program (Powell et al., $2018 b)$. However, there is a paucity of robust data on individual variation in cleaning behaviour and little information on lumpfish-salmon interactions (Overton et al., 2020), which has so far hampered progress towards the domestication of lumpfish as cleaner fish in aquaculture.

Domestication requires animals to adapt to life in captivity (Price, 1999), to express some behaviours and to suppress others (Belyaev, 1969; Jensen, 2014). Juvenile lumpfish aggregate in clumps and are sit and wait feeders (Powell et al., 2018a, 2018b). They are also poor swimmers (Hvas et al., 2018), have a low aerobic scope (Killen et al., 2007b), and use their suction cup to attach to shelters to conserve energy (Killen et al., 2007a). They are not well adapted to pursue prey, and do not normally interact with other fish species. To function as cleaner fish, lumpfish may need to overcome the fear of approaching a much larger "client" fish such as salmon, change their social behaviour, and become more exploratory, active and inquisitive. More specifically, delousing salmon requires lumpfish to take four successive steps: (1) leave the safety of being in a group and/or in a shelter, (2) approach a much larger and faster swimming fish (salmon), (3) identify clients that are infested with sea-lice, and (4) remove sea-lice from the skin of a fast-moving target. This sequence of events requires a particular skillset that not all individuals may possess, which might explain why only a small proportion of lumpfish clean parasitic sea-lice in salmon farms. We therefore hypothesized that only those individuals that have a bold personality, show exploratory behaviour, or are more active and willing to take risks may interact with salmon. Identifying those individuals might be possible through personality profiling sensu McCann (1992).

Personality profiling has been used to understand variation in personalities in humans (Costa Jr and McCrae, 1990; Neal et al., 2012; Van Dijk et al., 2017), but increasingly also in non-humans (Gosling and John, 1999), where it is also referred as temperament or stress coping styles (Dingemanse et al., 2010; Piersma and Drent, 2003). Personality traits are repeatable in many taxa, including fish (Castanheira et al., 2017; Elias et al., 2018; Vargas et al., 2018), which opens possibilities for artificial selection and the domestication of cleaner fish in aquaculture. We therefore tested if personality profiling using the five-factor model of non-human animal personality (Gosling and John, 1999) could be used to identify lumpfish better suited to behave as cleaner fish in salmon farms. We also tested if behaviours relevant to delousing were repeatable, as only repeatable behaviours can be inherited and modified by artificial selection during animal domestication (Belyaev, 1979).

\section{Materials and methods}

We used a four-step approach to assess the effects of lumpfish personality on lumpfish-salmon interactions. We first screened individually tagged lumpfish for five dimensions of animal personality (activity, sociality, anxiety, aggression, and boldness; Gosling and John, 1999) in the absence of salmon. We then retested fish after $\sim 1$ month to assess the repeatability of behaviour along each dimension, and generated personality scores from Principal Component Analysis to account for correlated behaviours. Finally, we examined whether lumpfish personality scores predicted lumpfish-salmon interactions.

\subsection{Source and rearing of experimental fish}

Lumpfish eggs were collected from wild adults caught in Iceland and the English Channel during the winter of 2016/2017, representing two genetically distinct populations (Whittaker et al., 2018). Adults were transported by road or boat using best practices (Jonassen et al., 2018) and were stripped on site (English stock) or shipped by plane (Iceland stock). Juveniles were reared for one year (mean weight $=114.8 \pm 9.7 \mathrm{~g}$ $\mathrm{SE})$ under recirculation aquaculture conditions. Water quality was monitored weekly and was maintained at 11-13 C temperature, 28-32 ppt salinity, $100 \%$ dissolved oxygen, $0.01 \mathrm{mg} / \mathrm{L}$ ammonia, $0.25 \mathrm{mg} / \mathrm{L}$ nitrite, and $0 \mathrm{mg} / \mathrm{L}$ nitrate. Photoperiod was set at 12D:12L, and fish were fed twice per day (Amber Neptune Skretting, UK) at $2 \%$ tank biomass, as recommended for the species (Powell et al., 2018b). In March 2017 lumpfish were allocated at random to eight $1500 \mathrm{~L}$ tanks (1.4 $\mathrm{m}$ diameter, $0.9 \mathrm{~m}$ depth; $33 \mathrm{fish} / \mathrm{tank}$; initial biomass $=75.37 \pm$ $\left.30.99 \mathrm{~g} / \mathrm{m}^{3}\right)$ and were individually marked with PIT tags $(7 \times 1.35 \mathrm{~mm}$, Loligo) under anaesthesia (2-Phenoxyethanol, $0.03 \mathrm{~mL} / \mathrm{L}$ ).

\subsection{Personality profiling}

We filmed 38 individually tagged lumpfish of two origins (Iceland, $\mathrm{n}$ $=16$; 10 females, 6 males; average starting weight $=121.1 \pm 39.9 \mathrm{~g}$; England, $\mathrm{n}=22$; 5 females, 17 males; average starting weight $=104.5 \pm$ 27.0 g) using a CCTV system (1080p camera, Sannce, Hong Kong). Fish were screened twice to quantify consistency in behavioural responses and estimate repeatability, first in March 2017 and then in May-June 2017. On each occasion, lumpfish were fasted for $12 \mathrm{~h}$ before testing in order to standardise hunger level, and were removed from their home tanks and placed inside the test arena using a hand net. The order in which lumpfish were tested was determined haphazardly, was different for each repeat, and was unknown to the investigator.

Personality profiling was conducted over four consecutive test phases, each lasting $10 \mathrm{~min}$, with different stimuli being introduced in separate phases as detailed in Table 1 . In phase 1 (neutral), a single lumpfish was introduced into one of two white rectangular test arenas $(\mathrm{L} 120 \mathrm{~cm} \times \mathrm{W} 55 \mathrm{~cm} \times \mathrm{D} 25 \mathrm{~cm}$ ) and was left to acclimatise for $10 \mathrm{~min}$ without any additional stimulus. The test arenas were divided into three equal zones using tape to facilitate video analysis, were each fitted with an air stone to maintain dissolved oxygen at $100 \%$ saturation and were surrounded by a black tarpaulin screen to minimise disruption. In phase 2 (shelter) a black smooth PVC panel (W55 cm $\times$ D25 cm) was introduced to one end of the test arena to provide a refuge, as lumpfish seek smooth, dark substrates (Imsland et al., 2015b). In phase 3 (mirror), a mirror (W55 $\mathrm{cm} \times \mathrm{D} 25 \mathrm{~cm}$ ) was added to the arena, opposite to the shelter. Finally, in phase 4 (novel), a novel object was placed at the

Table 1

Behavioural data collected over four test phases during personality profiling.

\begin{tabular}{|c|c|c|c|c|}
\hline Phase & Stimulus & Behaviour & $\begin{array}{l}\text { Personality } \\
\text { component }\end{array}$ & Definition \\
\hline \multirow[t]{4}{*}{1} & \multirow[t]{4}{*}{ None } & $\begin{array}{l}\text { Swimming } \\
\text { duration (secs) }\end{array}$ & Activity & $\begin{array}{l}\text { Total time moving } \\
\text { throughout } \\
\text { the tank }\end{array}$ \\
\hline & & $\begin{array}{l}\text { Crossing } \\
\text { frequency } \\
\text { (No.) }\end{array}$ & Activity & $\begin{array}{l}\text { Number of times } \\
\text { crossing the central } \\
\text { section of tank }\end{array}$ \\
\hline & & $\begin{array}{l}\text { Crossing } \\
\text { speed }(\mathrm{cm} / \mathrm{s})\end{array}$ & Activity & $\begin{array}{l}\text { Average speed crossing } \\
\text { the central section of the } \\
\text { tank }\end{array}$ \\
\hline & & $\begin{array}{l}\text { Perimeter } \\
\text { duration (s) }\end{array}$ & Anxiety & $\begin{array}{l}\text { Total time spent } \\
\text { swimming within } 10 \mathrm{~cm} \\
\text { of the tank wall }\end{array}$ \\
\hline 2 & Shelter & $\begin{array}{l}\text { Shelter } \\
\text { duration (s) }\end{array}$ & Anxiety & $\begin{array}{l}\text { Total time spent on or } \\
\text { within } 10 \mathrm{~cm} \text { of the } \\
\text { shelter }\end{array}$ \\
\hline \multirow[t]{3}{*}{3} & \multirow[t]{3}{*}{ Mirror } & $\begin{array}{l}\text { Mirror visits } \\
\text { (No.) }\end{array}$ & Sociality & $\begin{array}{l}\text { Number of approaches } \\
\text { to the mirror, excluding } \\
\text { bites and charges }\end{array}$ \\
\hline & & $\begin{array}{l}\text { Mirror } \\
\text { duration (s) }\end{array}$ & Sociality & $\begin{array}{l}\text { Total time spent within } \\
10 \mathrm{~cm} \text { of the mirror }\end{array}$ \\
\hline & & $\begin{array}{l}\text { Mirror bites } \\
\text { (No.) }\end{array}$ & Aggression & $\begin{array}{l}\text { Number of bites or } \\
\text { charges at the mirror }\end{array}$ \\
\hline \multirow[t]{3}{*}{4} & \multirow[t]{3}{*}{$\begin{array}{l}\text { Novel } \\
\text { Object }\end{array}$} & $\begin{array}{l}\text { Novel visits } \\
\text { (No.) }\end{array}$ & Boldness & $\begin{array}{l}\text { Number of approaches } \\
\text { to the novel object }\end{array}$ \\
\hline & & $\begin{array}{l}\text { Novel distance } \\
(\mathrm{cm})\end{array}$ & Boldness & $\begin{array}{l}\text { Average distance to the } \\
\text { novel object across 1- } \\
\text { min intervals }\end{array}$ \\
\hline & & $\begin{array}{l}\text { Novel latency } \\
\text { (s) }\end{array}$ & Boldness & $\begin{array}{l}\text { Time taken to first } \\
\text { approach the novel } \\
\text { object }\end{array}$ \\
\hline
\end{tabular}


centre of the arena (Fig. 1), a yellow golf ball in the first trial and a green Lego brick in the second repeat to prevent habituation. The four screening phases were conducted in the same order for every fish. Water was replaced between fish to avoid a build-up of stress hormones.

Behaviours were scored from video recordings using BORIS version 7.75 (Friard and Gamba, 2016) by one person who did not have knowledge of the identity of the fish or the trial conditions. We examined two metrics of activity in phase 1 (neutral): crossing speed across the central portion of the test arena $(\mathrm{cm} / \mathrm{s})$, and number of crosses between the three arena sections. We also measured activity by recording the total time spent swimming (s) throughout all four phases. Anxiety was assessed by recording the total time spent within $10 \mathrm{~cm}$ of the tank walls (thigmotaxis) during phase 1 (neutral) and also the total time spent within $10 \mathrm{~cm}$ of the black panel in phase 2 (shelter), as both are established methods of assessing anxiety in fish (Cianca et al., 2013; Godwin et al., 2012). To score aggression, we counted the number of agonistic actions (nips and charges) directed towards the mirror image (Rodriguez-Barreto et al., 2019) during phase 3 (mirror). The number of approaches to the mirror that did not result in body contact, as well as the time spent within close proximity $(<10 \mathrm{~cm})$ of the mirror during this phase were used as measures of sociality (Cattelan et al., 2017). As a measure of boldness, we counted the number of times individuals were within $10 \mathrm{~cm}$ of the novel object phase 4 (novel), the time latency to first approach the novel object, and average distance $(\mathrm{cm})$ from novel object at one minute intervals, as these are measures of neophobia that map well into the boldness-shyness continuum (Champneys et al., 2018). Collectively, these metrics capture variation in five dimensions of fish personality and have been associated with the expression of particular genes in the fish brain (Champneys et al., 2018; Rodriguez-Barreto et al., 2019). We also measured body mass ( $g$ ) and calculated specific growth rate (SGR\%), Lugert et al., 2016)) between the first and second repeated trials to account for the influence of feeding motivation on behaviour.

\subsection{Quantifying lumpfish-salmon interactions}

Atlantic salmon (Salmo salar) post-smolts $(\mathrm{n}=20$, mean mass $=175.6 \pm 37.6 \mathrm{~g} \mathrm{SE}$ ) were obtained from a commercial farm in Scotland in July 2017 and quarantined for one month in two $1500 \mathrm{~L}$ recirculating aquaculture tanks ( $1.4 \mathrm{~m}$ diameter, $0.9 \mathrm{~m}$ depth), at a density of 10 salmon per tank (initial biomass $=117.04 \pm 25.06 \mathrm{~g} / \mathrm{m}^{3}$
SE). In August 2017, the same tagged lumpfish that had previously been screened for personality traits $(n=38)$ were introduced singly into one of the two salmon tanks and recorded via CCTV for 20 min each. An ethogram based on previous studies on cleaner fish (Bshary and Côté, 2008; Horton, 2011) was constructed from the following three behaviours: time spent visually assessing salmon, often from multiple angles ("inspection, s"), time spent following salmon ("pursuit, s"), and number of times salmon fled when they were approached by lumpfish ("flee", no/min). Salmon were free of sea-lice to ensure that interactions with lumpfish were unaffected by variation in sea-lice loads, thereby ensuring consistency between replicated trials and between individuals. This would not have been possible if sea-lice loads had decreased as a result of lumpfish delousing, as this might have changed the behaviour of both species. All lumpfish were naive to salmon and salmon were also naive to lumpfish initially, but they were exposed to multiple lumpfish over the course of the study.

\subsection{Repeatability of behaviours}

$R$ version 4.0. ( $R$ Core Team, 2020) was used for all statistical analyses. To asses the repeatability $(R)$ of behaviours we used mixed models to identify significant behavioural covariates using the lme4 package. We employed linear mixed models (LMM) in the case of continuous behavioural metrics (e.g. duration of events, swimming speed and distance to novel object), and generalized linear mixed-models (GLMM) in the case of frequency of events (e.g. number of crosses across the test arena, and approaches to the mirror or the novel object). We included sex, stock origin (Iceland, England), specific growth rate (SGR, \%), and time of filming (days elapsed) as fixed factors, and test tank, home tank, and fish ID as random factors to account for repeated sampling and to control for grouping and potential non-independence of results. For each behavioural metric we identified minimal adequate models (Crawley, 2013) based on changes on AICc using the dredge function in the MuMIn package (Barton and Barton, 2015), and used the anova command and the Likelihood-Ratio Test (LRT) to compare these to null models without predictors. Model assumptions were checked by inspection of diagnostic plots with sjPlot (Lïdecke, 2020), and if these were not met, the significance of results was compared with robust estimates using the robustlmm package (Koller, 2016). The most plausible models were refitted by Restricted Maximum Likelihood (REML) to derive corrected

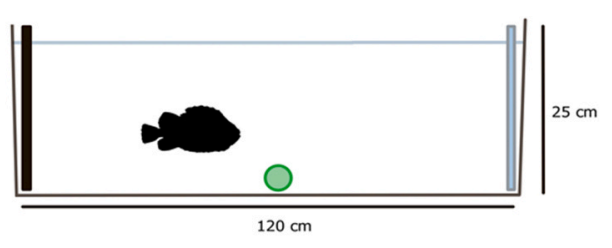

Phase 1 (Neutral)

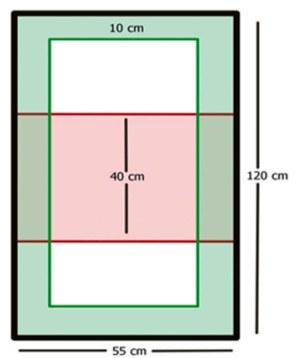

* Perimeter Duration

*Crossing Speed

*Crossing Frequency

*Swimming Duration

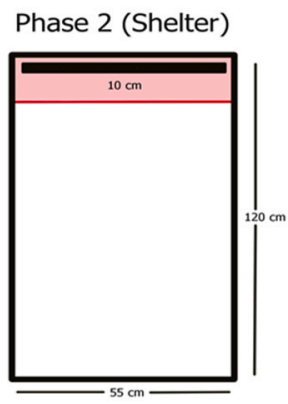

*Shelter Duration

*Swimming Duration
Phase 3 (Mirror)

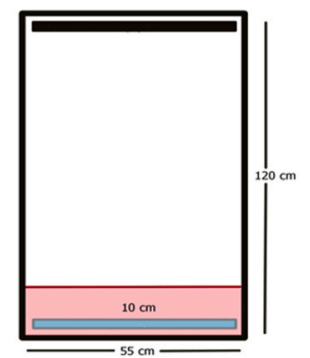

*Bite Frequency

*Mirror Duration

*Mirror Frequency

*Swimming Duration
Phase 4 (Novel)

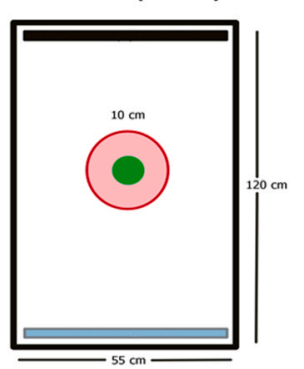

*Novel Frequency

*Novel Latency

*Novel Distance

*Swimming Duration
Fig. 1. Experimental design showing the four experimental phases, each lasting $10 \mathrm{~min}$ to asses variation in lumpfish personalities. In the neutral phase (phase 1), a perimeter was superimposed over the video footage to assess time spent near the walls (thigmotaxis) in an open field test and three equal sections were marked to measure crossing frequency and swimming speed. In the shelter phase (phase 2), the time spent within $10 \mathrm{~cm}$ of a black panel was recorded. In the mirror phase (phase 3 ), the time and frequency of agonistic and nonagonistic approaches to the mirror were recorded. In the novel phase (phase 4), the latency, frequency of approaches within $10 \mathrm{~cm}$ and distance to the novel object were recorded. 
probability values.

We used the $r p t R$ package (Stoffel et al., 2017) to calculate adjusted repeatability ( $R$; (Nakagawa and Schielzeth, 2010; Schuster et al., 2017)), using fish ID ( $\mathrm{n}=38)$ and repeat $(\mathrm{n}=2)$ as grouping variables, and any significant covariates identified above; 95\% confidence intervals were calculated via 1000 bootstraps, using a gaussian or a poison link, depending on the nature of the response variables. Behaviour was considered repeatable if the lower 95\% CI exceeded zero (Neumann et al., 2013) and repeatability was deemed low $(R<0.2)$, moderate ( $R=0.2-0.4$ ), or strong $(R>0.4)$, as in other studies of animal personalities (Bohn et al., 2017). Non-repeatable behaviours were excluded from analysis and repeatable behaviours were averaged to obtain a single value per fish.

\subsection{Personality scores and effects on lumpfish-salmon interactions}

Four repeatable behaviours identified from the personality profiling (crossing frequency, approaches to mirror, charges at mirror, and approaches to novel object were converted to frequency rates ( $\mathrm{No} / \mathrm{min})$ ) and used to generate personality scores via Principal Component Analysis to account for correlated behaviours and lack of independence (Gosling and John, 1999; Wilson et al., 2014). PC scores were rescaled from 0 to 1 using the scales package (Wickham et al., 2020) to facilitate comparisons and ensure equal weighting. To examine the effect of personality on lumpfish-salmon interactions we modelled the time lumpfish spent inspecting and pursuing salmon, as well as the salmon fleeing rate, as a function of lumpfish personality scores while statistically controlling for tank effects, stock origin, sex, growth rate, and time elapsed (to account for the cumulative exposure of salmon to lumpfish). We modelled each interaction separately via univariate LMMs and also together via MANOVA, and derived minimal adequate models via model simplification as described above for the repeatability study.

\subsection{Ethics declaration and approval for animal experiments}

This study adhered to the ARRIVE guidelines. All experimental procedures were approved by Swansea University, Animal Welfare Review Body, permit IP1617-27.

\section{Results}

\subsection{Repeatability of behaviours}

Crossing frequency was influenced by sex (parameter estimate (male) $=0.594 \pm 0.222, z=2.675, P=0.007$ ) and specific growth rate (parameter estimate $=0.525 \pm 0.195, z=2.688, P=0.007$ ), as females and faster growing fish were more active and crossed the test arena more frequently. Aggression decreased the second time the fish were tested against their mirror image (parameter estimate day$=-0.010 \pm 0.004, z=-2.352, P=0.019$ ), as did the frequency of non-aggressive mirror interactions (parameter estimate day $=$ $-0.005 \pm 0.001, z=-3.783, P<0.001$ ). Stock origin influenced the time individuals spent close to the tank perimeter (parameter estimate $\left.(\mathrm{UK})=56.18 \pm 22.72, t_{74}=2.473, P=0.016\right)$ and the number of approaches made to novel objects (parameter estimate $(\mathrm{UK})=-$ $1.611 \pm 0.386, z=-4.171, P<0.001$ ), with fish from the English Channel spending more time close to the walls and making fewer interactions with the novel object than fish from Icelandic origin. We therefore included sex and specific growth rate to estimate the adjusted repeatability of crossing frequency, geographic origin to estimate the repeatability of time spent close to the walls and frequency of encounters with the novel object, and time between trials to estimate the repeatability of interactions with the mirror image.

Of the 11 behaviours considered, 4 were repeatable corresponding to the activity, aggression, sociality and boldness dimensions of animal personality (Table 2). Crossing speed and time spent swimming were
Table 2

Repeatability (R) of behaviours used to generate personality scores for lumpfish. Repeatable behaviours are highlighted in bold.

\begin{tabular}{llllr}
\hline $\begin{array}{l}\text { Personality } \\
\text { component }\end{array}$ & Behaviour & \multicolumn{2}{l}{$\mathrm{R}$} & \multicolumn{2}{l}{$\mathrm{SE}$} \\
\hline Activity & Crossing speed (cm/s) & $\mathbf{0 . 6 5 1}$ & $\mathbf{0 . 0 9 7}$ & $<\mathbf{0 . 0 0 1}$ \\
& Crossing frequency (No.) & $\mathbf{0 . 2 7 8}$ & $\mathbf{0 . 1 2 7}$ & $\mathbf{0 . 0 1 8}$ \\
& Swimming duration (s) & $\mathbf{0 . 4 2 2}$ & $\mathbf{0 . 1 3 5}$ & $\mathbf{0 . 0 0 4}$ \\
Sociality & Approaches to mirror (No.) & $\mathbf{0 . 3 7 5}$ & $\mathbf{0 . 1 1 8}$ & $<\mathbf{0 . 0 0 1}$ \\
& Time close to mirror (s) & 0.000 & 0.080 & 1.000 \\
Anxiety & Time in arena perimeter (s) & 0.000 & 0.094 & 1.000 \\
& Time in shelter (s) & 0.177 & 0.135 & 0.124 \\
Aggression & Charges at mirror (No.) & $\mathbf{0 . 1 8 4}$ & $\mathbf{0 . 2 3 8}$ & $\mathbf{0 . 0 0 5}$ \\
Boldness & Approaches to novel object & $\mathbf{0 . 3 4 0}$ & $\mathbf{0 . 1 8 6}$ & $\mathbf{0 . 0 3 3}$ \\
& (No.) & & & \\
& Latency to novel object (s) & 0.184 & 0.137 & 0.163 \\
& Distance to novel object (cm) & 0.226 & 0.139 & 0.092 \\
\hline
\end{tabular}

strongly repeatable $(R>0.4)$, crossing frequency and frequency of interactions with the mirror and the novel object were moderately repeatable $(R=0.2-0.4)$, while aggression had a low repeatability $(\mathrm{R}=0.184)$. Distance to the novel object and the two measures of anxiety were not repeatable.

\subsection{Personality scores}

Significant positive correlations were found between two of the four repeatable behaviours (Table 3). Activity was positively correlated with sociality, and sociality was positively correlated with aggression. The first two principal components accounted for $68 \%$ of the variation in personality. PC1 was mostly driven by sociality (loading $=-0.64$ ) and activity (loading $=-0.58$ ), while PC2 mostly measured boldness (loading $=+0.94$ ) against aggression (loading $=-0.26$ ). PC3 was not significant in any of the models considered.

\subsection{Lumpfish-salmon interactions}

In the presence of salmon, most lumpfish engaged in visual inspections ( $89 \%$ of cases) and triggered one or more flight responses from salmon ( $89 \%$ of cases), but only $34 \%$ of lumpfish pursued salmon (Fig. 2). Lumpfish that spent more time inspecting salmon were also more likely to pursue them (Spearman rho $=0.550, \mathrm{df}=37$, $P<0.001)$. Time spent pursuing salmon was not explained by personality $\left(F_{7,30}=1.066, P=0.408\right)$ but lumpfish personality predicted the time spent inspecting salmon (PC2 estimate $=-18.151 \pm 8.861, t_{34.385}$ $=-2.048, P=0.048$ ), as well as the frequency of salmon flights (PC1 estimate $\left.=-1.005 \pm 0.242, t_{33.419}=-4.150, P<0.001\right)$ while statistically controlling for significant random tank effects. Individuals that were not afraid of the novel object during the initial behavioural profiling (neophilic) subsequently spent more time inspecting salmon than neophobic fish, as did the least aggressive lumpfish (PC2 - Fig. 3A). Salmon were more likely to flee in the presence of the most active and

Table 3

Correlation matrix between repeatable behaviours in lumpfish used to generate personality scores via principal component analysis. Upper diagonal displays the Pearson's correlation coefficient and lower diagonal the associated probabilities. Significant correlations are highlighted in bold.

\begin{tabular}{lcccc}
\hline Personality component & Activity & Sociality & Aggression & Boldness \\
\hline Activity(No. crosses/min) & & +0.440 & +0.210 & -0.046 \\
$\begin{array}{l}\text { Sociality(No. mirror } \\
\text { approaches/min) }\end{array}$ & $\mathbf{0 . 0 0 6}$ & & $+\mathbf{0 . 3 3 0}$ & +0.098 \\
$\begin{array}{c}\text { Aggression(No. mirror charges/ } \\
\text { min) }\end{array}$ & 0.210 & $\mathbf{0 . 0 4 4}$ & & -0.094 \\
$\begin{array}{c}\text { Boldness(No. novel object } \\
\text { approaches/min) }\end{array}$ & 0.780 & 0.560 & 0.580 & \\
\hline
\end{tabular}




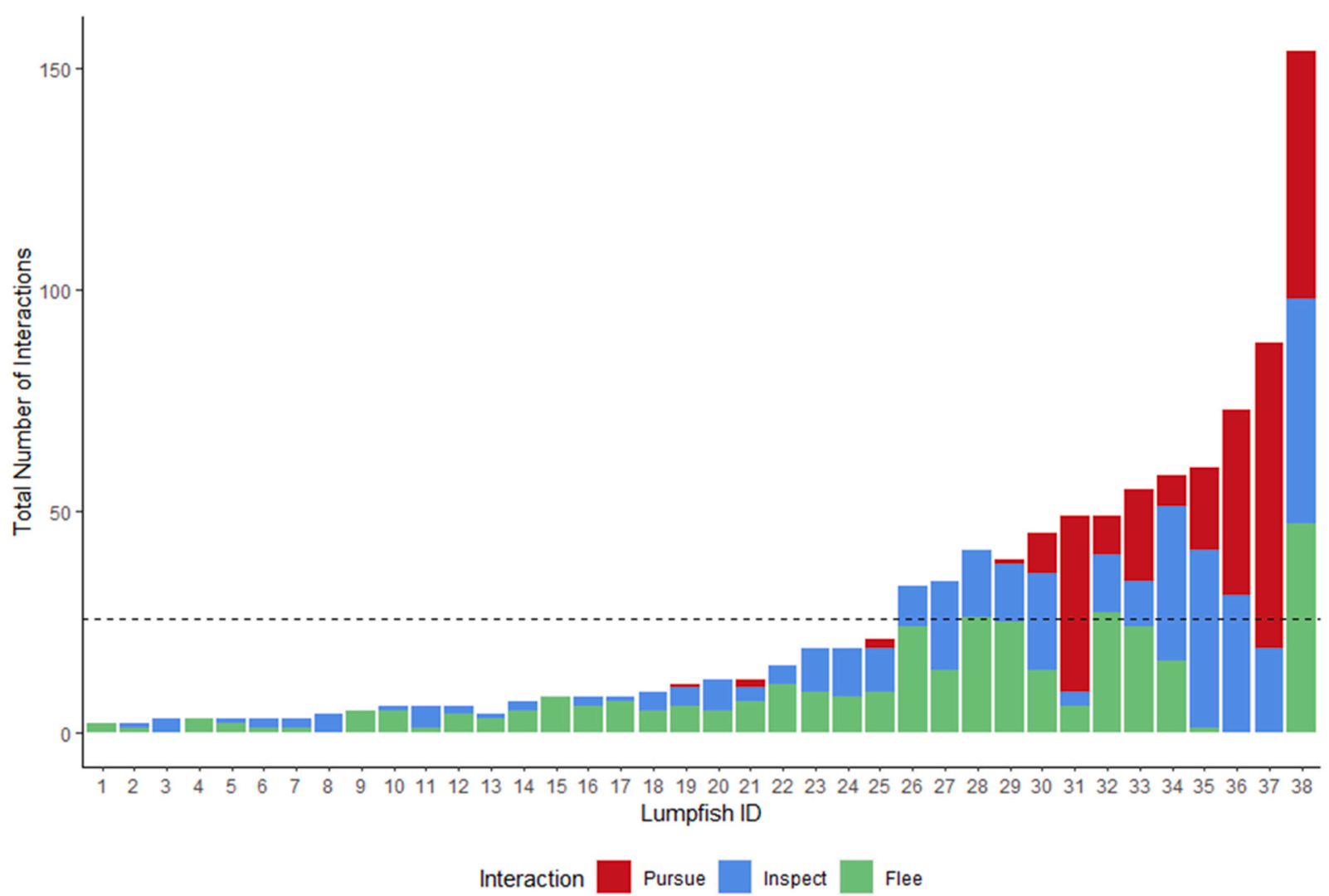

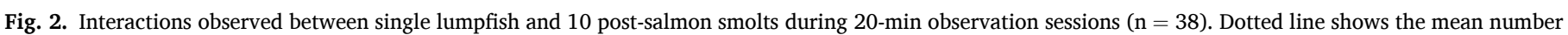
of interactions across all observations.

social individuals (PC1 - Fig. 3B).

MANOVA indicated that lumpfish-salmon interactions were predicted by personality (PC1 Pillai $=0.422, F_{3,33}=8.047, P<0.001$ ) and growth rate (Pillai $=0.332, F_{3,33}=5.480, P=0.004$ ), and provided a significantly better fit than a null model $\left(F_{6,68}=5.398, P<0.001\right)$.

\section{Discussion}

Our study shows that personality profiling can be used to predict how lumpfish interact with salmon and, possibly, whether they will make effective cleaner fish. In particular, we show that bold, neophilic lumpfish were more likely to inspect salmon, while the most active and social individuals were more likely to cause salmon to flee. As these behaviours were repeatable, and therefore likely heritable (Dohm, 2002; Lynch and Walsh, 1998), this suggests that artificial selection could be used to select better cleaner fish through domestication (Powell et al., 2018b). This is consistent with results that show that delousing behaviour is parentally controlled (Imsland et al., 2016b) and thus likely inherited. However, of the $37 \%$ of lumpfish that pursued salmon in our study, only $5 \%$ did so without causing salmon to flee. The challenge for domesticating lumpfish as cleaner fish, hence, might be how to select individuals that are bold enough to approach salmon in search of sea-lice, but not so aggressively as to cause salmon to flee.

The distribution of lumpfish-salmon interactions was highly skewed. The majority of lumpfish had limited interactions with salmon, but a few individuals interacted much more than the rest. For example, 7 individuals accounted for $60 \%$ of all the inspections, and just three individuals accounted for $60 \%$ of all the pursuits (Fig. 2) with only $37 \%$ of them pursuing salmon. This is consistent with results from diet analysis that indicate that only $\sim 30 \%$ of lumpfish consume sea-lice in salmon cages (Eliasen et al., 2018; Imsland et al., 2015a, 2014, 2016b), which our results suggest might be due to variation in animal personalities.
Boldness is a significant predictor of interactions in dedicated cleaner fish (Dunkley et al., 2019; Wilson et al., 2014), and it was repeatable in our study, suggesting it could targeted by artificial selection. Likewise, activity, exploratory behaviour and aggression were also repeatable, and several studies have shown that these traits are inherited in several fish species (Ariyomo et al., 2013; Bakker, 1986; Chervet et al., 2011; Magnhagen, 2012; Sutrisno et al., 2011).

Breeding programs could establish pedigree lines from lumpfish families with proven delousing ability in sea-cages (Imsland et al., 2016b) and select for stocks with desirable behaviours. For example, fish from Icelandic origin in our study spent significantly more time interacting with the novel object than fish from the English Channel, suggesting there may be genetic differences in risk-taking behaviour that could be improved through selective breeding, though serendipity cannot be ruled out. There is no information on the heritability of any behavioural traits in lumpfish, but the estimated repeatability for swimming duration $(R=0.422)$ and frequency of approaches to the novel object $(R=0.340)$ could be used as upper values for narrow sense heritability $\left(h^{2}\right)$ of pursuing and inspection behaviours, respectively (Dohm, 2002; Lynch and Walsh, 1998). Using these values to estimate the response to artificial selection suggests that selecting the top $10 \%$ most active and boldest lumpfish for breeding could increase the time lumpfish spend inspecting and pursuing salmon 1.4-3.5 times within one generation, respectively. In this sense, protocols could be developed to screen lumpfish personalities in hatcheries, and exclude from subsequent rearing and deployment those individuals less likely to approach salmon. Currently, many lumpfish do not engage in cleaning behaviour, and selecting for behaviours that make good cleaners could drastically reduce the number of lumpfish required on farms, reducing costs and improving welfare (Garcia de Leaniz et al., 2021).

The selection of "elite" lines of cleaner fish that are particularly bold and active, but not overly aggressive, could be done in different ways. 
(A)

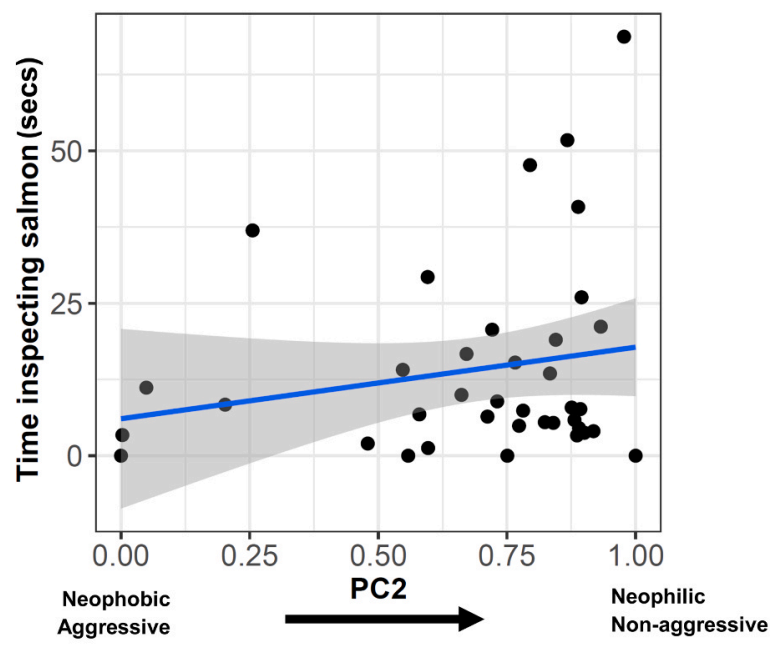

(B)

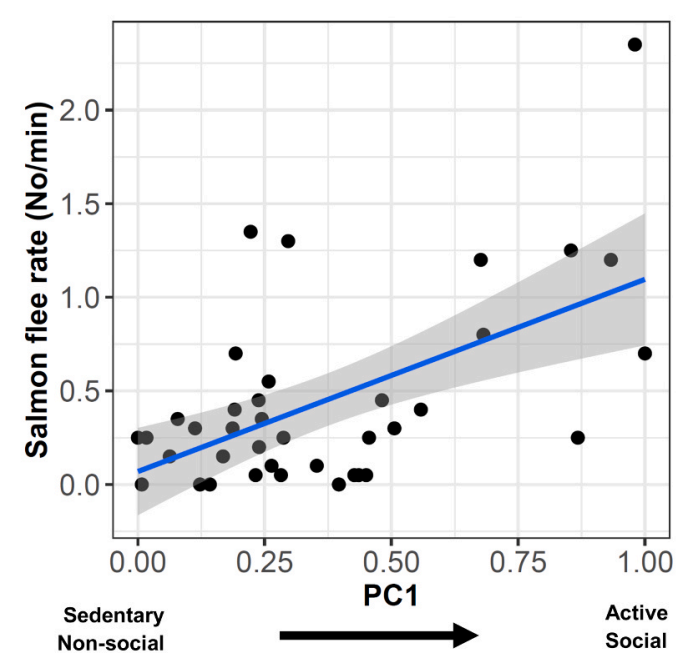

Fig. 3. Relationship between significant lumpfish personality scores (PC1, PC2) derived from behavioural profiling and (A) time spent by lumpfish inspecting salmon, and (B) frequency of salmon flights in response to lumpfish approaches.

For example, one way boldness could be selected is by targeting lumpfish with high metabolic rate (Hvas et al., 2018) and low cortisol response (Gutierrez Rabadan et al., 2021), or more efficiently, by targeting genes associated with boldness and aggression (Rodriguez-Barreto et al., 2019). Metabolic rate can be used to predict boldness in some fish species (Killen et al., 2012) and can also be used to predict foraging mode (active vs passive) in lumpfish (Killen et al., 2007a). This is important, as presumably only active lumpfish that swim to pursue their prey (as opposite to passively foraging while clinging) will make efficient cleaners, although studies are needed to establish to what extent high metabolic rate equates to boldness in lumpfish.

One reason why some farmed lumpfish do not survive the salmon production cycle in sea cages is because they fail to feed and adapt to a novel environment (Imsland et al., 2020, 2019b). Failure of hatchery-reared lumpfish to adapt to the sea-cage environment could be due to phenotypic mismatch, as seen in other species (Stringwell et al., 2014), but steps can be taken to reduce maladaptation. Fish personality is shaped by both intrinsic and extrinsic drivers (Brown et al., 2011), most notably through early experience (Dingemanse et al., 2009; Huntingford and Garcia de Leaniz, 1997), and one way maladaptation could be reduced is by manipulating the rearing environment through environmental and social enrichment. Environmental enrichment can modify risk-taking behaviours in fish very rapidly (Roberts et al., 2011, 2014) and this could perhaps be used to suppress fear and enhance cleaning behaviour in lumpfish. For example, feeding sea-lice and live prey to lumpfish prior to cage deployment was found to promote subsequent delousing behaviour (Imsland et al., 2019), and previous exposure to salmon may also reduce stress and improve cohabitation (Staven et al., 2019). Likewise, prior exposure to lumpfish might allow salmon to become accustomed to the presence of cleaner fish and reduce fleeing behaviour.

In general, intensive fish farming seems to modify fish behaviours in predictable ways, by altering patterns of gene expression in the fish brain that can be targeted by selective breeding (Rodriguez-Barreto et al., 2019). Social enrichment prior to deployment in sea cages could be used to modify behaviours and facilitate adaptation of lumpfish to sea cages. For example, living in socially impoverished habitats decreases cleaning efficacy in wrasse (Wismer et al., 2014), and the same could happen in lumpfish.

Cleaning behaviour could also be improved through size selection and manipulation of growth rate. We found that faster growing lumpfish interacted more with salmon than slower growing fish, suggesting that selecting for fast growing lumpfish might also select for more active, bolder lumpfish which might perform better as cleaner fish. Lumpfish hatcheries typically supply relatively small juveniles to sea-cages (approx. $20 \mathrm{~g}$ ), as this is thought to be an optimal size for cleaning behaviour (Imsland et al., 2016c). However, more recent studies indicate that body size accounts for little variation in delousing rates, and that smaller lumpfish are more likely to have empty stomachs (Eliasen et al., 2018). Larger cleaner wrasse also interact more with salmon (Whittaker et al., 2021) and a re-assessment of the optimal size for lumpfish deployment warrants further study.

In summary, our results indicate that only a small proportion of lumpfish interact with salmon in ways that are conductive to cleaning behaviour. As some personality traits were found to be repeatable, this might open the possibility for artificially selecting cleaner fish with desired behaviours, a process that our study suggests could be rapid. Failure to feed on sea-lice is a major cause of emaciation and mortality among lumpfish used as cleaner in salmon farming (Garcia de Leaniz et al., 2021; Gutierrez Rabadan et al., 2021), and behavioural profiling could be used to select better cleaner fish and make the industry more sustainable. Further studies, using pedigree analysis of variation in delousing rates, could be used to estimate the heritability of personality traits and their association with sea-lice removal. More work is also needed to examine the welfare implications of using facultative cleaner fish for sea-lice control in salmon farming.

\section{Declaration of Competing Interest}

The authors declare that they have no known competing financial interests or personal relationships that could have appeared to influence the work reported in this paper.

\section{Data availability}

The data files for this study have been deposited in figshare https://doi.org/10.6084/m9.figshare.14626839.v1.

\section{Acknowledgements}

We are grateful to Jessica Minett and Kayla Fairfield for assistance with the personality screening and to Paul Howes, Becky Stringwell and the CSAR technicians for logistic support and help with fish husbandry. The study was funded by Marine Harvest Scotland through the LUMPFISH Project and the Welsh Government via the European Regional Development Fund (SMARTAQUA Operation). The funders had no role in study design, data collection and analysis, decision to publish, or preparation of the manuscript. 


\section{References}

Ariyomo, T.O., Carter, M., Watt, P.J., 2013. Heritability of boldness and aggressiveness in the zebrafish. Behav. Genet. 43, 161-167.

Bakker, T.C., 1986. Aggressiveness in sticklebacks (Gasterosteus aculeatus L.): a behaviour-genetic study. Behaviour 98, 1-144.

Barton K., Barton MK, 2015. Package 'MuMIn'.

Belyaev, D.K., 1969. Domestication of animals. Science 5, 47-52.

Belyaev, D.K., 1979. Destabilizing selection as a factor in domestication. J. Hered. 70, 301-308.

Bohn, S.J., Webber, Q.M., Florko, K.R., Paslawski, K.R., Peterson, A.M., Piche, J.E., Menzies, A.K., Willis, C.K., 2017. Personality predicts ectoparasite abundance in an asocial sciurid. Ethology 123, 761-771.

Brown, C., Laland, K., Krause, J., 2011. Fish Cognition and Behavior. John Wiley \& Sons. Bshary, R., Côté, I.M., 2008. New perspectives on marine cleaning mutualism. In: Magnhagen, C., Braithwaite, V., Forsgren, E., Kapoor, B. (Eds.), Fish Behaviour. Science Publishers, Enfield, pp. 563-592.

Castanheira, M.F., Conceição, L.E.C., Millot, S., Rey, S., Bégout, M.-L., Damsgård, B., Kristiansen, T., Höglund, E., Øverli, Ø., Martins, C.I.M., 2017. Coping styles in farmed fish: consequences for aquaculture. Rev. Aquac. 9, 23-41.

Cattelan, S., Lucon-Xiccato, T., Pilastro, A., Griggio, M., 2017. Is the mirror test a valid measure of fish sociability? Anim. Behav. 127, 109-116.

Champneys, T., Castaldo, G., Consuegra, S., Garcia de Leaniz, C., 2018. Densitydependent changes in neophobia and stress-coping styles in the world's oldest farmed fish. R. Soc. Open Sci. 5, 181473.

Chervet, N., Zöttl, M., Schürch, R., Taborsky, M., Heg, D., 2011. Repeatability and heritability of behavioural types in a social cichlid. Int. J. Evolut. Biol. 2011.

Cianca, V., Bartolini, T., Porfiri, M., Macrì, S., 2013. A robotics-based behavioral paradigm to measure anxiety-related responses in zebrafish. PLoS One 8, e69661.

Compassion in World Farming, 2018. Scottish Parliament. EISF038. Environment, Climate Change and Land Reform Committee. Environmental Impacts of Salmon Farming. Written Submission from Compassion in World Farming. CIFW, p. 4. https://archive2021.parliament.scot/S5_Environment/Inquiries/038_Compassion_i n World Farming.pdf.

Costa Jr., P.T., McCrae, R.R., 1990. Personality disorders and the five-factor model of personality. J. Personal. Disord. 4, 362-371.

Crawley, M.J., 2013. The R Book. John Wiley \& Sons, Chichester, UK, p. 975.

Davenport, J., 1985. Synopsis of biological data on the lumpsucker, Cyclopterus lumpus (Linnaeus, 1758). Food Agric. Org.

Dingemanse, N.J., Van der Plas, F., Wright, J., Réale, D., Schrama, M., Roff, D.A., Van de Zee, E., Barber, I., 2009. Individual experience and evolutionary history of predation affect expression of heritable variation in fish personality and morphology. Proc. $\mathrm{R}$. Soc. B: Biol. Sci. 276, 1285-1293.

Dingemanse, N.J., Kazem, A.J., Réale, D., Wright, J., 2010. Behavioural reaction norms: animal personality meets individual plasticity. Trends Ecol. Evol. 25, 81-89.

Dohm, M., 2002. Repeatability estimates do not always set an upper limit to heritability. Funct. Ecol. 273-280.

Dunkley, K., Ioannou, C., Whittey, K., Cable, J., Perkins, S., 2019. Cleaner personality and client identity have joint consequences on cleaning interaction dynamics. Behav. Ecol.

Elias, A., Thrower, F., Nichols, K.M., 2018. Rainbow trout personality: individual behavioural variation in juvenile Oncorhynchus mykiss. Behaviour 155, 205-230.

Eliasen, K., Danielsen, E., Johannesen, Á., Joensen, L.L., Patursson, E.J., 2018. The cleaning efficacy of lumpfish (Cyclopterus lumpus L.) in Faroese salmon (Salmo salar L.) farming pens in relation to lumpfish size and seasonality. Aquaculture 488, $61-65$.

European Union Reference Laboratory for Fish Diseases, 2016. Cleaner Fish in Aquaculture: Health Management and Legislative Issues. National Veterinary Institute, Technical University of Denmark, Copenhagen, p. 35.

Friard, O., Gamba, M., 2016. BORIS: a free, versatile open-source event-logging software for video/audio coding and live observations. Methods Ecol. Evol. 7 (1325), 1330.

Garcia de Leaniz, C., Gutierrez Rabadan, C., Barrento, S.I., Stringwell, R., Howes, P.N., Whittaker, B.A., Minett, J.F., Smith, R.G., Pooley, C.L., Overland, B.J., Biddiscombe, L., Lloyd, R., Consuegra, S., Maddocks, J.K., Deacon, P.T.J., Jennings, B.T., Rey Planellas, S., Deakin, A., Moore, A.I., Phillips, D., Bardera, G., Castanheira, M.F., Scolamacchia, M., Clarke, N., Parker, O., Avizienius, J., Johnstone, M., Pavlidis, M., 2021. Addressing the welfare needs of farmed lumpfish: knowledge gaps, challenges and solutions. Rev. Aquac.

Godwin, J., Sawyer, S., Perrin, F., Oxendine, S.E., Kezios, Z.D., 2012. Adapting the Open Field Test to Assess Anxiety-related Behavior in Zebrafish, pp. 181-189.

Gosling, S.D., John, O.P., 1999. Personality dimensions in nonhuman animals a crossspecies review. Curr. Dir. Psychol. Sci. 8, 69-75.

Gutierrez Rabadan, C., Spreadbury, C., Consuegra, S., Garcia de Leaniz, C., 2021. Development, validation and testing of an operational welfare score index for farmed lumpfish Cyclopterus lumpus L. Aquaculture 531, 735777.

Horton, S., 2011. Factors affecting advertising in Indonesian adult and juvenile bluestreak cleaner wrasse (Labroides dimidiatus). Biosci. Horiz. 4 (90), 98.

Huntingford, F.A., Garcia de Leaniz, C., 1997. Social dominance, prior residence and the acquisition of profitable feeding sites in juvenile Atlantic salmon. J. Fish Biol. 51, 1009-1014.

Hvas, M., Folkedal, O., Imsland, A., Oppedal, F., 2018. Metabolic rates, swimming capabilities, thermal niche and stress response of the lumpfish, Cyclopterus lumpus. Biol. Open 7, bio036079.

Imsland, A.K., Reynolds, P., Eliassen, G., Hangstad, T.A., Foss, A., Vikingstad, E. Elvegård, T.A., 2014. The use of lumpfish (Cyclopterus lumpus L.) to control sea lice
(Lepeophtheirus salmonis Krøyer) infestations in intensively farmed Atlantic salmon (Salmo salar L.). Aquaculture 424-425, 18-23.

Imsland, A.K., Reynolds, P., Eliassen, G., Arne, T., Vigdisdatter, A., Foss, A., Vikingstad, E., Anders, T., 2015a. Feeding preferences of lumpfish (Cyclopterus lumpus L.) maintained in open net-pens with Atlantic salmon (Salmo salar L.). Aquaculture 436, 47-51.

Imsland, A.K., Reynolds, P., Eliassen, G., Hangstad, T.A., Nytrø, A.V., Foss, A., Vikingstad, E., Elvegård, T.A., 2015b. Assessment of suitable substrates for lumpfish in sea pens. Aquac. Int. 23, 639-645.

Imsland, A.K., Reynolds, P., Eliassen, G., Hangstad, T.A., Jónsdóttir, Ó.D.B., Elvegård, T. A., Lemmens, S.C.A., Rydland, R., Nytrø, A.V., 2016a. Investigation of behavioural interactions between lumpfish (Cyclopterus lumpus) and goldsinny wrasse (Ctenolabrus rupestris) under controlled conditions. Aquac. Int. 24, 1509-1521.

Imsland, A.K., Reynolds, P., Eliassen, G., Mortensen, A., Hansen, Ø.J., Puvanendran, V., Hangstad, T.A., Jónsdóttir, Ó.D.B., Emaus, P.A., Elvegård, T.A., Lemmens, S.C.A., Rydland, R., Nytrø, A.V., Jonassen, T.M., 2016b. Is cleaning behaviour in lumpfish (Cyclopterus lumpus) parentally controlled? Aquaculture.

Imsland, A.K., Reynolds, P., Nytrø, A.V., Eliassen, G., Hangstad, T.A., Jónsdóttir, Ó.D.B., Emaus, P.-A., Elvegård, T.A., Lemmens, S.C.A., Rydland, R., Jonassen, T.M., 2016c. Effects of lumpfish size on foraging behaviour and co-existence with sea lice infected Atlantic salmon in sea cages. Aquaculture 465, 19-27.

Imsland, A.K., Frogg, N., Stefansson, S.O., Reynolds, P., 2019a. Improving sea lice grazing of lumpfish (Cyclopterus lumpus L.) by feeding live feeds prior to transfer to Atlantic salmon (Salmo salar L.) net-pens. Aquaculture 511, 734224.

Imsland, A.K., Reynolds, P., Lorentzen, M., Eilertsen, R.A., Micallef, G., Tvenning, R., 2020. Improving survival and health of lumpfish (Cyclopterus lumpus L.) by the use of feed blocks and operational welfare indicators (OWIs) in commercial Atlantic salmon cages. Aquaculture, 735476.

Imsland, A.K.D., Hanssen, A., Nytrø, A.V., Reynolds, P., Jonassen, T.M., Hangstad, T.A., Elvegård, T.A., Urskog, T.C., Mikalsen, B., 2018. It works! Lumpfish can significantly lower sea lice infestation in large-scale salmon farming. Biol. Open 7 bio036301.

Imsland, A.K.D., Frogg, N., Stefansson, S.O., Reynolds, P., 2019b. Improving sea lice grazing of lumpfish (Cyclopterus lumpus L.) by feeding live feeds prior to transfer to Atlantic salmon (Salmo salar L.) net-pens. Aquaculture 511, 734224.

Jensen, P., 2014. Behavior genetics and the domestication of animals. Annu. Rev. Anim. Biosci. 2, 85-104.

Johannesen, Á., Arge, R., Eliasen, K., 2018. Rearing, farm application, and behaviour of lumpfish (Cyclopterus lumpus) in the Faroes. In: Treasurer, J.W. (Ed.), Cleaner Fish Biology and Aquaculture Applications. 5M Publishing Ltd., Sheffield, pp. 429-443.

Jonassen, T., Remen, M., Lekva, A., Steinarsson, A., Árnason, T., 2018. Transport of lumpfish and wrasse. In: Treasurer, J. (Ed.), Cleaner Fish Biology and Aquaculture Applications. 5M Publishing, pp. 319-335.

Killen, S.S., Brown, J.A., Gamperl, A.K., 2007a. The effect of prey density on foraging mode selection in juvenile lumpfish: balancing food intake with the metabolic cost of foraging. J. Anim. Ecol. 76, 814-825.

Killen, S.S., Costa, I., Brown, J.A., Gamperl, A.K., 2007b. Little left in the tank: metabolic scaling in marine teleosts and its implications for aerobic scope. Proc. R. Soc. B: Biol. Sci. $431-438$.

Killen, S.S., Marras, S., Ryan, M.R., Domenici, P., McKenzie, D.J., 2012. A relationship between metabolic rate and risk-taking behaviour is revealed during hypoxia in juvenile European sea bass. Funct. Ecol. 26, 134-143.

Koller, M., 2016. robustlmm: an R package for robust estimation of linear mixed-effects models. J. Stat. Softw. 75, 1-24.

Lüdecke, M.D., 2020. Package 'sjPlot' Data Visualization for Statistics in Social Science.

Lugert, V., Thaller, G., Tetens, J., Schulz, C., Krieter, J., 2016. A review on fish growth calculation: multiple functions in fish production and their specific application. Rev. Aquac. 8, 30-42.

Lynch, M., Walsh, B., 1998. Genetics and Analysis of Quantitative Traits. Sinauer, Sunderland, MA.

Magnhagen, C., 2012. Personalities in a crowd: what shapes the behaviour of Eurasian perch and other shoaling fishes? Curr. Zool. 58, 35-44.

McCann, J.T., 1992. Criminal personality profiling in the investigation of violent crime: recent advances and future directions. Behav. Sci. Law 10, 475-481.

Morado, N., Mota, P.G., Soares, M.C., 2019. The rock cook wrasse centrolabrus exoletus aims to clean. Front. Ecol. Evol. 7.

Nakagawa, S., Schielzeth, H., 2010. Repeatability for Gaussian and non-Gaussian data: a practical guide for biologists. Biol. Rev. 85 (935), 956.

Neal, A., Yeo, G., Koy, A., Xiao, T., 2012. Predicting the form and direction of work role performance from the Big 5 model of personality traits. J. Organ. Behav. 33, 175-192.

Neumann, C., Agil, M., Widdig, A., Engelhardt, A., 2013. Personality of wild male crested macaques (Macaca nigra). PLoS One 8, e69383.

OneKind, 2018. Cleaner Fish Welfare on Scotland's Salmon Farms. OneKind, Edinburgh, p. 24 .

Overton, K., Barrett, L.T., Oppedal, F., Kristiansen, T.S., Dempster, T., 2020. Sea lice removal by cleaner fish in salmon aquaculture: a review of the evidence base. Aquacult. Environ. Interact. 12, 31-44.

Piersma, T., Drent, J., 2003. Phenotypic flexibility and the evolution of organismal design. Trends Ecol. Evol. 18, 228-233.

Powell, A., Pooley, C., Scolamacchia, M., Garcia de Leaniz, C., 2018a. Review of lumpfish biology. In: Treasurer, J.W. (Ed.), Cleaner Fish Biology and Aquaculture Applications. 5M Publishing Ltd., Sheffield, pp. 98-121.

Powell, A., Treasurer, J.W., Pooley, C.L., Keay, A.J., Lloyd, R., Imsland, A.K., Garcia de Leaniz, C., 2018b. Use of lumpfish for sea-lice control in salmon farming: challenges and opportunities. Rev. Aquac. 10, 683-702. 
Price, E.O., 1999. Behavioral development in animals undergoing domestication. Appl. Anim. Behav. Sci. 65, 245-271.

R Core Team, 2020. R: A Language and Environment for Statistical Computing. Version 4.0.0 (2020-04-24). R Foundation for Statistical Computing, Vienna, Austria.

Roberts, L.J., Taylor, J., Garcia de Leaniz, C., 2011. Environmental enrichment reduces maladaptive risk-taking behavior in salmon reared for conservation. Biol. Conserv. 144, 1972-1979.

Roberts, L.J., Taylor, J., Gough, P.J., Forman, D.W., Garcia de Leaniz, C., 2014. Silver spoons in the rough: can environmental enrichment improve survival of hatchery Atlantic salmon Salmo salar in the wild? J. Fish Biol. 85, 1972-1991.

Rodriguez-Barreto, D., Rey, O., Uren-Webster, T.M., Castaldo, G., Consuegra, S., Garcia de Leaniz, C., 2019. Transcriptomic response to aquaculture intensification in Nile tilapia. Evolut. Appl. 12, 1757-1771.

Schuster, A.C., Carl, T., Foerster, K., 2017. Repeatability and consistency of individual behaviour in juvenile and adult Eurasian harvest mice. Sci. Nat. 104, 10.

Staven, F.R., Nordeide, J.T., Imsland, A.K., Andersen, P., Iversen, N.S., Kristensen, T., 2019. Is habituation measurable in lumpfish Cyclopterus lumpus when used as cleaner fish in Atlantic salmon Salmo salar Aquaculture? Front. Vet. Sci. 6.

Stoffel, M.A., Nakagawa, S., Schielzeth, H., 2017. rptR: repeatability estimation and variance decomposition by generalized linear mixed-effects models. Methods Ecol. Evol. 8 (1639), 1644.

Stranden AL, 2020. Norwegian fish farmers reprimanded for poor treatment of cleaner fish. In: sciencenorway.com.forskning.no.

Stringwell, R., Lock, A., Stutchbury, C.J., Baggett, E., Taylor, J., Gough, P.J., Garcia de Leaniz, C., 2014. Maladaptation and phenotypic mismatch in hatchery-reared Atlantic salmon Salmo salar released in the wild. J. Fish Biol. 85, 1927-1945.

Sutrisno, R., Wisenden, B.D., Sailer, C.D., Radenic, S.J., 2011. Maternal inheritance and exploratory-boldness behavioural syndrome in zebrafish. Behaviour 148, 1443-1456.
Treasurer, J., 2018a. Cleaner fish in aquaculture review and looking to the future. In: Treasurer, J.W. (Ed.), Cleaner Fish Biology and Aquaculture Applications. 5M Publishing Ltd., Sheffield, pp. 483-495.

Treasurer, J., 2018b. An introduction to sea lice and the rise of cleaner fish. In: Treasurer, J.W. (Ed.), Cleaner Fish Biology and Aquaculture Applications. 5M Publishing Ltd., Sheffield, pp. 3-25.

Van Dijk, F.E., Mostert, J., Glennon, J., Onnink, M., Dammers, J., Vasquez, A.A., Kan, C., Verkes, R.J., Hoogman, M., Franke, B., 2017. Five factor model personality traits relate to adult attention-deficit/hyperactivity disorder but not to their distinct neurocognitive profiles. Psychiatry Res. 258, 255-261.

Vargas, R., Mackenzie, S., Rey, S., 2018. 'Love at first sight': the effect of personality and colouration patterns in the reproductive success of zebrafish (Danio rerio). PLoS One 13, e0203320.

Whittaker, B.A., Consuegra, S., Garcia de Leaniz, C., 2018. Genetic and phenotypic differentiation of lumpfish (Cyclopterus lumpus) across the North Atlantic: implications for conservation and aquaculture. PeerJ 6, e5974.

Whittaker, B.A., Maeda, S., Boulding, E.G., 2021. Strike a pose: does communication by a facultative cleaner fish, the cunner wrasse (Tautogolabrus adspersus), facilitate interaction with Atlantic salmon (Salmo salar)? Appl. Anim. Behav. Sci. 236, 105275.

Wickham H., Seidel D., RStudio, 2020. Package 'scales' version 1.1.1.

Wilson, A.D.M., Krause, J., Herbert-Read, J.E., Ward, A.J.W., 2014. The personality behind cheating: behavioural types and the feeding ecology of cleaner fish. Ethology 120, 904-912.

Wismer, S., Pinto, A.I., Vail, A.L., Grutter, A.S., Bshary, R., 2014. Variation in cleaner wrasse cooperation and cognition: influence of the developmental environment? Ethology 120, 519-531. 